\title{
ANALISIS WACANA KRITIS LIRIK LAGU MOCKINGBIRD KARYA EMINEM
}

\author{
Ria Saraswati \\ Universitas Indraprasta PGRI \\ riri.saraswati21@gmail.com
}

\begin{abstract}
ABSTRAK
Penelitian ini bertujuan untuk mengetahui maksud penggunaan kata-kata tertentu dan Black English serta slang Amerika dalam lirik lagu tersebut dan hubungannya dengan latar belakang kehidupan Eminem dahulu. Penelitian ini menggunakan metode penelitian kualitatif deskriptif. Analisis penelitian ini terfokus pada kata-kata yang digunakandan ragam bahasa Black English dan slang Amerika yang terdapat dalam lirik lagu Mockingbird.. Penulis mengaitkan teori analisis wacana kritis dengan teori transkultural Pennycook, black English, dan slang Amerika, untuk menganalisis lirik lagu tersebut dan melihat penyebaran budaya hiphop. Hasil penelitian membuktikan bahwa terdapat hubungan antara latar belakang kehidupan Eminem dengan penggunaan kata-kata tertentu dalam lirik lagunya.
\end{abstract}

Kata Kunci: analisis wacana, black English, bahasa slang Amerika, Mockingbird

\begin{abstract}
The aims of this study is to determine the purpose of the use of certain words, Black English and American slang in Mockingbird lyrics and its relationship to the background of Eminem's life. The analysis of this study focused on the words used, the variety of Black English and American slang in Mockingbird lyrics. The applied theory refers to Pennycook's critical discourse analysis, black English, and American slang transcultural theories. The result show that there is a relationship between the background of Eminem's life with the use of certain words in the lyrics of the song.
\end{abstract}

Key Words: discourse analysis, Black English, American slang, Mockingbird

\section{PENDAHULUAN \\ Latar Belakang}

Lagu merupakan salah satu bentuk karya sastra karena pada dasarnya lagu adalah sebuah puisi yang dinyanyikan. Lagu dibuat oleh pengarang dengan tujuan untuk menyampaikan pesan kepada para pendengarnya. Lagu sebagai media yang universal dan efektif, dapat menuangkan gagasan, pesan, dan ekspresi pengarang kepada pendengar melalui lirik, nada dan bagaimana cara lagu itu dibawakan. Lirik lagu pada dasarnya memiliki kesamaan dengan puisi. Maka mulai dari pemilihan kata atau diksi, gaya bahasa dan rima sama dengan puisi.

Lirik lagu akan mengomunikasikan beberapa konsep di antaranya menceritakan sesuatu, membawa kesan pengalaman pengarang dan menimbulkan komentar atau opini pendengarnya. Lirik lagu juga sarat dengan pesan-pesan tersembunyi pengarang atau ungkapan hati pengarang. Komunikasi yang terjadi melalui lagu adalah saat pendengar atau penikmat musik dapat memahami pesan atau maksud dari lagu tersebut sehingga terbentuk interaksi dunia dalam seseorang dengan dunia luar. Pesan yang terkandung dalam sebuah lagu isinya bisa mengajak, memprovokasi dan mengajari sesuatu kepada para pendengarnya. Agar pendengar dapat menerima pesan atau memahami lagu dengan tepat, diperlukan kajian lebih dalam terhadap lirik lagu. Kajian tersebut dapat dianalisis dengan menggunakan analisis wacana.

Wacana adalah rangkaian kalimat yang saling berkaitan dan mengandung satuan bahasa terlengkap, terbesar dan tertinggi yang dapat disampaikan baik secara lisan (pidato, ceramah, 
khotbah, dialog) maupun tertulis (cerpen, novel, buku, surat, dokumen tertulis) yang memiliki kohesi dan koherensi yang baik serta berkesinambungan. Wacana adalah kesatuan makna (semantis) antarbagian di dalam suatu bangun bahasa (Yuwono, 2005: 25). Istilah wacana dipergunakan untuk mencakup bukan hanya percakapan atau obrolan, tetapi juga pembicaraan di muka umum, tulisan, serta upaya-upaya formal seperti laporan ilmiah dan sandiwara atau lakon. Agar dapat mengetahui makna yang terkandung di dalam sebuah wacana maka diperlukan sebuah penelitian lebih lanjut. Penelitian yang berkaitan dengan wacana adalah analisis wacana kritis atau disebut sebagai Critical Discourse Analysis.

Analisis wacana kritis ini dikembangkan oleh Norman Fairclough, seorang sosiolinguis Inggris, pada tahun 1980an. Analisis Wacana Kritis adalah sebuah teori atau pendekatan yang digunakan untuk menganalisis sebuah teks dalam konteks sosio-kultural (Fairclough, 1995: 7). Menurut Fairclough (1995), di dalam sebuah wacana terdapat praktik sosial yang mengubah pengetahuan, identitas, dan relasi sosial (relasi kuasa) yang sudah ada. Selain itu, wacana juga terbentuk dan dipengaruhi oleh struktur dan praktik sosial lainnya. Di dalam Analisis Wacana Kritis, wacana bukan hanya dilihat sebagai sebuah studi bahasa saja, melainkan juga berhubungan dan berkaitan dengan konteks. Wacana memiliki hubungan dialektis dengan dimensi sosial. (Philips dan Jorgensen, 2002: 65). Analisis Wacana Kritis (AWK) ini memiliki tiga dimensi di dalamnya, yaitu teks, praktik wacana, dan praktik sosio-kultural.

Bahasa juga membawa dampak ideologi dan politik di dalamnya. Misalnya, seseorang yang berkata "Saya haus" dan orang lain yang mengatakan "Ambilkan saya segelas air dingin" akan terlihat perbedaannya. Orang yang mengatakan "Saya haus" bisa saja hanya berkata pada temannya yang sederajat, sedangkan orang yang mengatakan "Ambilkan saya segelas air dingin" mengatakannya kepada anak buahnya. Dari situ terlihat adanya unsur politik seseorang yang memerintahkan orang lain untuk melakukan sesuatu. Saat ini, setiap orang akan sadar dengan identitas dan keberadaannya di dunia ini. Dengan ideologi yang berbeda-beda, tiap orang ingin menunjukkan eksistensinya di dunia. Seperti misalnya anak muda yang cinta akan kebebasan ingin menunjukkan eksistensinya dengan mengikuti tren yang ada saat ini, seperti gaya berpakaian, kebiasaan merokok, dan lain sebagainya. Demikian juga dengan Eminem, yang merupakan seorang penyanyi hiphop kulit putih Amerika. Ia mengusung ideologi anti-rasis dengan menggunakan musik hiphop untuk menembus pasar musik Amerika. Hiphop merupakan budaya orang kulit hitam Amerika. Eminem sejak kecil tinggal dan hidup di daerah Detroit, Amerika, yang mayoritas penduduknya adalah orang kulit hitam. Namun dalam hal ini, Eminem merasa bagian dari masyarakat kulit hitam Amerika sehingga ia menggunakan hiphop untuk menunjukkan identitasnya sebagai bagian dari komunitas hiphop orang kulit hitam dari Detroit.

Budaya orang kulit hitam Amerika ini juga sangat kental dengan ragam bahasa Inggrisnya yang berbeda dari standard English (SE). Madeleine Magnusson (2008) dalam penelitiannya yang berjudul African American Vernacular English in Black and White Rap Lyrics menyebutkan bahwa AAVE berbeda dengan bahasa Inggris standar dalam beberapa hal; secara gramatikal, fonologis dan leksikal. Contoh Fitur gramatikal di AAVE adalah invarian be, negasi ganda, dan penggunaan kata ganti posesif yang berbeda. Bahasa Inggris yang digunakan orang kulit hitam ini disebut dengan African American Vernacular English (AAVE) atau Black English Vernacular (BEV) yang dalam penelitian ini akan digunakan istilah BEV. Ragam bahasa Inggris baru yang berbeda dari bahasa Inggris standar ini muncul akibat penjajahan yang dilakukan oleh bangsa kulit putih yang berbahasa Inggris sehingga para korban imperialism menyerap bahasa Inggris yang didengarnya, maka muncullah ragam bahasa Inggris baru. Dalam tesisnya yang berjudul African American Vernacular English in the Lyrics of African American Popular Music, Matthew Feldman (2002) menyimpulkan bahwa artis rap menggunakan Black English untuk mengekspesikan solidaritas dengan warga Afrika Amerika dan perlawanan terhadap budaya kulit putih. Black English ini juga sering kita jumpai dalam lirik lagu hiphop misalnya dalam lirik lagu Soulja's Story yang dinyanyikan oleh 2Pac terdapat kalimat Now you losin friends. Kalimat tersebut berbeda dengan bahasa Inggris standar (SE), yang 
membedakannya adalah kata losin yang seharusnya ditulis losing dan menurut tata bahasa yang benar kalimat tersebut seharusnya now you are losing friends. Inilah salah satu budaya orang kulit hitam yang melekat pada lagu hiphop, yaitu cara pengucapan dan tata bahasa yang berbeda dengan bahasa Inggris standar.

Budaya hiphop ini menurut Pennycook (2007:102) memiliki beberapa elemen di dalamnya, yaitu DJ-ing, MC-ing (rapping), break-dancing, dan graffiti. Namun fokus utama Pennycook bukan pada elemen budaya hiphop tetapi lebih kepada arus lintas budaya atau transcultural flows. Istilah transcultural flows, arus transkultural, atau arus lintas budaya ini digunakan Pennycook (2007: 6) untuk membahas bagaimana sebuah bentuk budaya bergerak, berubah, dan digunakan kembali untuk membentuk sebuah identitas yang baru dalam konteks yang beragam. Lebih jauh, ia juga mengatakan bahwa arus lintas budaya tidak hanya merujuk pada penyebaran bentuk-bentuk tertentu dari budaya lintas batas, atau adanya kesamaan superkultural (bentuk budaya yang melampaui lokalitas), melainkan untuk proses borrowing (peminjaman), blending (pencampuran), remaking (memperbaharui) dan returning (kembali) pada proses alternatif produksi budaya.

Fokus Pennycook dalam arus transkultural atau arus lintas budaya ini bukan hanya pada perpindahan suatu bentuk budaya secara global saja, tapi juga melihat bagaimana penerimaan lokal terhadap bentuk budaya tersebut. Transkulturasi ini bisa diartikan sebagai sebuah fenomena pada daerah kontak (contact zone) yang menjelaskan bagaimana kelompok subordinat atau kelompok marginal menyeleksi dan menemukan budaya dari materi yang ditularkan oleh budaya dominan atau budaya metropolitan kepada mereka (Pratt 1992 dalam Pennycook 2007: 7). Sementara itu, menurut Pennycook sendiri, transkulturasi merupakan aliran hubungan budaya dari seluruh konteks global. Meskipun sulit, masih ada kemungkinan untuk menentukan berapa banyak unsur budaya yang akan diambil dan akan digunakan untuk apa (Pratt dalam Pennycook 2007: 46).

Pennycook memberikan contoh bagaimana arus transkultural dari budaya hiphop, yang berasal dari Bronx Amerika, ini terjadi di beberapa penjuru dunia, contohnya di Australia dan Asia (Malaysia, Jepang, dan Korea). Misalnya dalam contoh lirik lagu Too Phat (kelompok penyanyi rap asal Malaysia) berikut ini yang menggunakan budaya tradisi Malaysia di dalam lirik lagu hiphop-nya (Pennycook, 2007: 5):

Ya! Kau tertarik dengan lirik, baut lu terbalik

Mr. Malique, Joe Flizzow dan T-Bone spit it menarik

Kita hit terbaik bisa bikin goyang

Tukang karut moden bercerita pasti girang

Proses transkultural yang terjadi pada lirik lagu tersebut adalah cara menyanyikannya yang diadaptasi dari elemen budaya hiphop Amerika, yaitu teknik menyanyi rap.

Hiphop sangat erat kaitannya dengan rap, karena dalam hiphop rap adalah sebuah teknik untuk menyanyikan lirik lagu hiphop. Lirik-lirik lagu rap identik dengan ekspresi pribadi si penyanyi ataupun si pencipta lagu. Sering kali lirik lagu ini berisi kata-kata kasar yang sebenarnya adalah ekspresi dari perasaan si penyanyi. Eminem yang bernama asli Marshall Mathers, merupakan penyanyi rap kulit putih yang sempat kontroversi karena lagu-lagunya yang menggunakan kata- kata kasar, sehingga tidak pantas untuk didengar anak-anak di bawah umur yang hanya bisa menangkap apa yang mereka dengar tanpa menyaringnya lebih dulu. Lirik lagu yang diusung Eminem memiliki keunikan dan ciri tersendiri bila dibandingkan dengan lirik lagu rap lainnya. Keunikan itu dapat dilihat dari seringnya Eminem menggunakan Black English dalam lirik lagunya walaupun ia adalah penyanyi berkulit putih dan latar belakang kehidupan pribadinya memberikan pengaruh yang cukup besar dalam lirik lagu ciptaannya. Inilah yang menjadi fokus penelitian, teori utama dalam penelitian ini adalah teori analisis wacana kritis Norman Fairclough. Teori utama ini juga didukung oleh teori lain seperti Black English (BEV) dan slang Amerika, serta transcultural Alastair Pennycook. 


\section{Rumusan Masalah}

Permasalahan yang akan dibahas dalam penelitian ini adalah sebagai berikut.

1. Bagaimanakah pengaruh latar belakang kehidupan Eminem dalam lirik lagu karyanya?

2. Kata-kata dan ragam Bahasa Inggris seperti apakah yang dipilih Eminem untuk mengekspresikan diri dalam lagu-lagunya?

3. Efek apakah yang terjadi pada pendengar akibat pemilihan dan penggunaan kata-kata yang digunakan oleh Eminem?

\section{Tujuan Penelitian}

Tujuan penelitian ini sebagai berikut.

1. Untuk mengetahui bagaimana pengaruh kehidupan Eminem dalam pemilihan kata untuk liriklagunya.

2. Untuk menganalisis penggunaan kata-kata kasar tertentu, BEV atau black English, dan slang Amerika yang digunakan Eminem dalam lirik lagunya serta mengetahui alasan Eminem memilih kata-katatersebut.

3. Untuk mengetahui efek sosial seperti apa yang terjadi akibat kata-kata yang digunakan oleh Eminem tersebut.

\section{Tinjauan Pustaka}

Analisis wacana kritis ini dikembangkan oleh Norman Fairclough, seorang sosiolinguis Inggris, pada tahun 1980an. Analisis Wacana Kritis adalah sebuah teori atau pendekatan yang digunakan untuk menganalisis sebuah teks dalam konteks sosio-kultural (Fairclough, 1995: 7). Menurut Fairclough (1995), di dalam sebuah wacana terdapat praktik sosial yang mengubah pengetahuan, identitas, dan relasi sosial (relasi kuasa) yang sudah ada. Selain itu, wacana juga terbentuk dan dipengaruhi oleh struktur dan praktik sosial lainnya. Di dalam Analisis Wacana Kritis, wacana bukan hanya dilihat sebagai sebuah studi bahasa saja, tetapi juga berhubungan dan berkaitan dengan konteks. Wacana memiliki hubungan dialektis dengan dimensi sosial (Philips dan Jorgensen, 2002: 65). Analisis Wacana Kritis (AWK) ini memiliki tiga dimensi di dalamnya, yaitu teks, praktik wacana, dan praktik sosio-kultural.

Fokus dalam tahapan analisis Fairclough terbagi menjadi dua dimensi besar, yaitu peristiwa komunikatif dan urutan wacana. Analisis peristiwa komunikatif memfokuskan pada aspek penggunaan bahasa dan isi serta mengaitkannya pada aspek sosial dan budaya, sedangkan analisis urutan wacana melihat hubungan antara wacana yang berbeda dalam teks yang disusun sedemikian rupa untuk menyampaikan makna dari teks yang dibuat. Hal ini juga memperlihatkan bagaimana sebuah praktik sosio-kultural digambarkan dalam wacana.

\section{Transkultural}

Istilah transcultural flows ini digunakan oleh Pennycook (2007) dalam bukunya yang berjudul Global Englishes and Transcultural Flows. Istilah transcultural flows, arus transkultural, atau arus lintas budaya ini digunakan Pennycook (2007: 6) untuk membahas bagaimana sebuah bentuk budaya bergerak, berubah, dan digunakan kembali untuk membentuk sebuah identitas yang baru dalam konteks yang beragam. Lebih jauh, ia juga mengatakan bahwa arus lintas budaya tidak hanya merujuk pada penyebaran bentuk-bentuk tertentu dari budaya lintas batas, atau adanya kesamaan superkultural (bentuk budaya yang melampaui lokalitas), melainkan untuk proses borrowing (peminjaman), blending (pencampuran), remaking (memperbaharui) dan returning (kembali) pada proses alternatif produksi budaya.

Fokus Pennycook dalam arus transkultural atau arus lintas budaya ini bukan hanya pada perpindahan suatu bentuk budaya secara global saja, tapi juga melihat bagaimana penerimaan lokal terhadap bentuk budaya tersebut. Transkulturasi ini bisa diartikan sebagai sebuah fenomena 
pada daerah kontak (contact zone) yang menjelaskan bagaimana kelompok subordinat atau kelompok marjinal menyeleksi dan menemukan budaya dari materi yang ditularkan oleh budaya dominan atau budaya metropolitan kepada mereka (Pratt 1992 dalam Pennycook 2007: 7). Sementara itu, menurut Pennycook sendiri, transkulturasi merupakan aliran hubungan budaya dari seluruh konteks global. Meskipun sulit, masih ada kemungkinan untuk mennetukan berapa banyak unsur budaya yang akan diambil dan akan digunakan untuk apa (Pratt dalam Pennycook 2007: 46).

Pennycook memberikan contoh bagaimana arus transkultural dari budaya hiphop, yang berasal dari Bronx Amerika, ini terjadi di beberapa penjuru dunia, contohnya di Australia dan Asia (Malaysia, Jepang, dan Korea). Misalnya dalam contoh lirik lagu Too Phat (kelompok penyanyi rap asal Malaysia) berikut ini yang menggunakan budaya tradisi Malaysia di dalam lirik lagu hiphop-nya (Pennycook, 2007: 5):

Ya! Kau tertarik dengan lirik, baut lu terbalik

Mr. Malique, Joe Flizzow dan T-Bone spit it menarik

Kita hit terbaik bisa bikin goyang

Tukang karut moden bercerita pasti girang

Proses transkultural yang terjadi pada lirik lagu tersebut adalah cara menyanyikannya yang diadaptasi dari elemen budaya hiphop Amerika, yaitu teknik menyanyi rap.

\section{African American Vernicular English (Black English Vernicular)}

Menurut Kamus Oxford Advance Learner, African American adalah orang Amerika yang berasal dari ras atau suku bangsa yang memiliki kulit gelap, aslinya berasal dari Afrika (A.S Hornby 2000). Sementara itu, vernacular atau vernakular adalah bahasa yang digunakan di daerah tertentu atau oleh kelompok tertentu, terutama yang bukan bahasa resmi atau bahasa tertulis (A.S Hornby 2000). African American VernacularEnglish (AAVE) atau lebih sering dikenal dengan istilah Black English ini adalah bahasa Inggris yang digunakan oleh orang kulit hitam Amerika. Menurut Labov (1972), struktur bahasa Inggris dalam AAVE ini berbeda dengan struktur dalam bahasa Inggris standar atau standard English (SE).

Dalam AAVE atau Black English terdapat perubahan fonetik $n g / \mathrm{y} /$ di akhir leksikal kata yang berimbuhan -ing, pada morfem -ing, yang merupakan fonetik velar nasal, menjadi fonetik alveolar nasal /n/, misalnya pada kalimat I was playing. Dalam struktur Black English ini, dilafalkan menjadi I was playin'. Selain itu, lebih jauh Labov (1972) mengatakan bahwa ada pula ciri lain dari AAVE, yaitu penghilangan kopula to be seperti is, am, atau are, pada sebuah kalimat, misalnya:

\begin{tabular}{|c|c|}
\hline SE & AAVE \\
\hline They are gone & They gone \\
\hline Who are you & Who you \\
\hline You are crazy & You crazy \\
\hline
\end{tabular}

Sementara itu, dalam bentuk negasi, AAVE biasanya menggunakan istilah ain't yang kalau dalam bahasa Inggris standar menggunakan am not, isn't, dan aren't. Labov (1972) juga menambahkan bahwa penggunaan ain't pada kalimat negatif biasanya juga digunakan oleh beberapa penuturnya sebagai pengganti don't, doesn't, dan juga didn't. Dalam bentuk negasi AAVE juga dapat ditemui negasi ganda atau double negation. Bentuk ini dianggap wajar dalam struktur AAVE atau Black English, tetapi memiliki maksud yang berbeda dengan negasi ganda yang ada pada struktur SE. Pada SE, negasi ganda biasanya berarti positif, sedangkan pada AAVE negasi ganda tetap berarti negatif. Misalnya adalah pada kalimat I don't disagree. Dalam SE, kalimat tersebut berrati I agree atau "saya setuju", namun dalam AAVE, kalimat tersebut tetap berarti negatif, "saya tidak setuju".

Dillard (1972) mengatakan bahwa beberapa auxiliary seperti have dalam SE sering digantikan posisinya dengan is dalam Black English, seperti contoh berikut. 


\begin{tabular}{|c|c|}
\hline SE & BEV \\
\hline Have you seen him? & Is you see(n) him? \\
\hline Have they gone there? & Is they gone there? \\
\hline
\end{tabular}

AAVE atau Black English ini juga berperan dalam kemunculan ekspresi- ekspresi slang dalam bahasa Inggris. Menurut Kamus Oxford Advanced Learner, slang adalah very informal words and expressions that are more common in spoken language, especially used by a particular group of people, for example, children, criminals, soldiers, etc. Dalam lirik lagu pada penelitian ini, bahasa Inggris slang yang ditemukan adalah bahasa Inggris slang Amerika. Seperti juga Bahasa Indonesia yang memiliki bahasa gaul yang biasa digunakan oleh para remaja, bahasa slang ini juga biasanya digunakan oleh sekelompok komunitas tertentu misalnya seperti remaja. Contoh kata-kata slang dalam kamus slang Oxford misalnya Dutchy, Dutchee, Dutchie yang digunakan untuk menyebut orang imigran asal Jerman di Amerika. Dapat kita simpulkan bahwa bentuk slang ini merupakan bentuk informal yang biasanya digunakan dalam bentuk lisan oleh sekelompok orang tertentu.

\section{METODE PENELITIAN}

Penelitian ini merupakan jenis penelitian deskriptif kualitatif dengan menggunakan analisis wacana kritis. Penelitian deskriptif kualitatif merupakan penelitian yang dilakukan untuk memahami suatu fenomena dari subjek penelitian secara utuh dengan cara mendeskripsikannya dalam bentuk kata-kata dan bahasa dan dengan memanfaatkan berbagai metode alamiah (Moleong, 2001: 6). Data yang digunakan dalam penelitian ini terdiri atas data primer dan data sekunder. Data primer dalam penelitian ini berupa lirik lagu Mockingbird dinyayikan oleh Eminem yang diambil dari album Encore. Sementara itu, data sekunder dalam penelitian ini berupa tinjauan-tinjauan pustaka yang mendukung teori dan informasi lain yang mendukung analisis data. Data sekunder yang digunakan untuk mendukung teori dan informasi lainnya berkenaan dengan penelitian ini merupakan sumber yang didapat dari buku-buku dan juga artikel-artikel dari internet.

\section{HASIL DAN PEMBAHASAN}

Analisis data menggunakan teori analisis wacana kritis (Critical Discourse Analysis) Fairclough yang di dalamnya mencakup teori tata bahasa fungsional (Systemic Grammar) Halliday, teori transkultural Pennycook, dan juga analisis penggunaan Black English (BEV) serta slang Amerika. Proses analisis dilakukan dalam tiap bait lagu untuk memudahkan proses analisis. Secara lebih spesifik, model analisis wacana kritis Norman Fairclough, mencakup tiga dimensi. Dimensi pertama adalah teks (text). Pada dimensi pertama ini, teks dianalisis dengan memperhatikan kosakata, semantik, tata kalimat, koherensi, dan juga kohesivitas. Dimensi kedua adalah praktik wacana (discourse practice). Pada dimensi kedua ini, akan dilihat kandungan nilai ideologi atau paham yang mendasari proses produksi dan konsumsi teks tersebut. Sementara itu, pembentuk wacananya bisa berupa latar belakang pengetahuan, interpretasi, dan konteks. Dimensi praktik wacana, penulis akan menganalisis interpretasi dan konteks yang terkandung dalam kata pada lirik lagunya. Dimensi terakhir adalah praktik sosio-kultural, yaitu melihat bagaimana konteks sosial di luar teks bisa memengaruhi wacana.

Analisis tata bahasa Halliday, teori transkultural, dan Black English serta slang Amerika akan terintegrasi dalam analisis data secara keseluruhan, karena teks lirik lagu dianalisis tiap bait. Analisis juga akan menunjukkan interpretasi dari lirik lagu Mockingbird. Lirik lagu ini terdapat dalam album Encore. Lagu ini memiliki enam bait di dalamnya. lirik lagu Mockingbird menggambarkan tentang cinta dan kasih sayang, seorang ayah kepada gadis kecilnya. Menceritakan betapa seorang ayah, yang mungkin bagi kebanyakan orang adalah bad guy, namun ternyata memiliki cinta yang begitu besar pada sang anak. 


\section{Bait 1}

(1) Yeah

(2) I know sometimes things may not always make sense to you right now

(3) But hey, what daddy always tell you?

(4) Straighten up little soldier

(5) Stiffen up that upper lip

(6) What you crying about?

(7) You got me

Pada baris pertama, Eminem menggunakan kata yeah yang merupakan kata yang biasa digunakan dalam situasi percakapan informal. Yeah merupakan kata slang Amerika sebagai pengganti kata Yes. Penggunaan kata yeah sangat wajar terjadi pada situasi percakapan informal untuk menyatakan persetujuan seperti yang terjadi dalam lagu. Kata yeah digunakan untuk menjawab kalimat pada baris kedua. Struktur bahasa Inggris pada baris kedua merupakan struktur SE yang benar. Eminem menggunakan kata informal kembali pada baris ketiga yaitu penggunaan kata hey. Hey merupakan bentuk informal dari hello, hey merupakan bentuk salam yang paling informal. Biasanya digunakan untuk menunjukkan keakraban. Dalam kalimat But hey, what daddy always tell you?, penggunaan kata hey menunjukkan bahwa sebagai seorang ayah, Eminem menunjukkan bahwa tidak ada jarak antara dirinya dan putrinya. Dalam kalimat tersebut juga terdapat sebuah conjuction, yaitu but yang digunakan untuk menunjukkan kemungkinan apa pun selain apa yang sedang dinyatakan. Dalam kalimat kedua I know sometimes things may not always make sense to you right now dapat diartikan 'Aku tahu bahwa terkadang banyak hal mungkin tidak selalu masuk di akal bagi dirimu' lalu dilanjutkan dengan But hey, what daddy always tell you? Yang dapat diartikan 'Tapi hey, ingat apa yang selalu ayah katakan padamu?' Kedua kalimat ini saling berkaitan, Eminem ingin mengatakan pada putrinya bahwa walaupun banyak hal tidak masuk akal baginya sekarang namun kemungkinan terbaik akan selalu ada.

Baris ke empat terdapat frasa Straighten up little soldier. Kata little soldier dapat diartikan sebagai 'tentara kecil' digunakan sebagai panggilan kesayangan bagi putrinya. Baris berikutnya Stiffen up that upper lip adalah ungkapan di mana biasanya ketika orang berada di ambang air mata (tanda ingin menangis), bibir mereka mulai bergetar, Eminem menganggap ini merupakan tanda kelemahan. Oleh karena itu, ia menyebut putrinya dengan little soldier dengan harapan putrinya tidak menjadi anak yang lemah. Baris berikutnya merupakan kelanjutannya dari frasa diatasnya What you crying about?. Dalam kalimat tersebut seharusnya ditambahkan tobeare. Seharusnya, yang benar struktur kalimat tersebut adalah What are you crying about?. Kata tobe are dalam kalimat tersebut harus ditambahkan karena kalimat What you crying about? adalah kalimat verbal, di mana dalam kalimat verbal memerlukan penambahan kata to be sebelum kata kerja. Kata to be are dalam kalimat tersebut dihilangkan karena sudah ada konteks dan pengetahuan yang sama antara pembuat teks yang juga sekaligus penyanyi dan juga pendengar lagu. Konteks dan pengetahuan yang sama antara tokoh dalam produksi dan konsumsi teks lagu adalah dalam kasus kata tobe are yang tidak dimunculkan dalam teks, namun sudah dapat dimengerti oleh penikmat teks lagu tersebut.

Kalimat pada baris berikutnya You got me menggunakan struktur bahasa Inggris SE yang benar. Kata kerja got merupakan kata kerja bentuk lampau dari get. Kalimat ini merupakan kelanjutan dari rangkaian peristiwa pada dua frasa dan satu kalimat sebelumnya. Kalimat You got me dapat diartikan sebagai 'ayah ada di sini', maksud dalam kalimat ini adalah Eminem mengatakan pada putrinya untuk tetap tegar dan jangan menangis karena ia akan ada selalu untuk putrinya.

Dalam bait pertama ini, terlihat bahwa Eminem ingin putrinya tidak terlihat lemah dan mudah menangis karena baginya menangis adalah tanda kelemahan. Bait pertama ini juga menunjukkan bahwa Eminem tidak ingin putrinya khawatir dengan keadaan di sekitarnya karena 
perubahan dalam hidup yang terjadi sangat cepat dan membingungkan sang anak. Perpisahannya dengan sang istri lalu menjadi seorang rapper terkenal adalah situasi yang membuat putrinya bingung. Namun, sebagai seorang ayah, ia akan selalu hadir dalam kehidupan putrinya.

\section{Bait kedua}

(1) Hailie I know you miss your mom and I know you miss your dad

(2) When I'm gone but I'm trying to give you the life that I never had

(3) I can see you're sad, even when you smile, even when you laugh

(4) I can see it in your eyes, deep inside you want to cry

(5) 'Cause you're scared, I ain't there?

(6) Daddy's with you in your prayers

(7) No more crying, wipe them tears

(8) Daddy's here, no more nightmares

(9) We gonna pull together through it, we gonna do it

(10) Laney uncles crazy, ain't he?

(11) Yeah but he loves you girl and you better know it

(12) We're all we got in this world

(13) When it spins, when it swirls

(14) When it whirls, when it twirls

(15) Two little beautiful girls

(16) Lookin' puzzled, in a daze

(17) I know it's confusing you

(18) Daddy's always on the move, mamma's always on the news

(19) I try to keep you sheltered from it but somehow it seems

(20) The harder that I try to do that, the more it backfires on me

(21) All the things growing up his daddy that he had to see

(22) Daddy don't want you to see but you see just as much as he did

(23) We did not plan it to be this way, your mother and me

(24) But things have gotten so bad between us

(25) I don't see us ever being together ever again

(26) Like we used to be when we was teenagers

(27) But then of course everything always happens for a reason

(28) I guess it was never meant to be

(29) But it's just something we have no control over and that's what destiny is

(30) But no more worries, rest your head and go to sleep

(31) Maybe one day we'll wake up and this will all just be a dream

Kalimat pertama Hailie I know you miss your mom and I know you miss your dad, Eminem menyebut sebuah nama Hailie yang merupakan nama putrinya dengan sang istri Kimberly. Lagu Mockingbird dibuat Eminem khusus untuk putrinya, Hailie. Dalam kalimat tersebut dapat pula kita jumpai bahasa Inggris informal yaitu mom dan $\mathrm{dad}$. Mom dan dad adalah bahasa informal untuk menyebut mother dan father. Penggunaan bahasa informal pada lagu merupakan hal yang lumrah untuk dilakukan karena penggunaan kata ini lebih nyaman didengar dibandingkan dengan mother dan father. Dalam kalimat Hailie I know you miss your mom and I know you miss your dad memiliki arti 'Hailie aku tahu kau merindukan ibu dan ayah', terlihat jelas bahwa sebagai seorang ayah, Eminem tahu bahwa putrinya merindukan orang tuanya. Klausa berikutnya menjelaskan klausa di atas, When I'm gone but I'm trying to give you the life that I never had. Klausa tersebut menjelaskan mengapa Hailie merindukan ayahnya. Eminem selalu tidak ada dirumah karena ingin memeberikan kehidupan yang lebih baik bagi putrinya, kehidupan yang tidak pernah ia rasakan. Eminem sendiri hidup dalam kemiskinan bersama ibunya yang merupakan orang tua tunggal. 
Kalimat I can see you're sad, even when you smile, even when you laugh dapat diartikan sebagai'Aku dapat melihat kesedihan, dalam senyum dan tawa mu'. Kalimat ini merupakan bentuk ekspresi Eminem yang mengetahui bahwa putrinya bersedih walaupun ia tersenyum dan tertawa. Kalimat berikutnya merupakan lanjutan dari rangkaian peristiwa di kalimat sebelumnya. Kalimat I can see it in your eyes, deep inside you want to cry memiliki arti 'Karena matamu tidak dapat berbohong, jauh dalam lubuk hatimu kau ingin menangis'. Maksud kalimat ini adalah sebagai seorang ayah, ia tahu bahwa putrinya bersedih hanya dengan melihat arti dibalik tatapan matanya. Bahasa Inggris yang digunakan dalam kedua kalimat tersebut sudah mengikuti aturan bahasa Inggris standar (SE).

Penggunaan Black English (BEV) terdapat dalam klausa 'Cause you're scared, I ain't there?, Lookin' puzzled, in a daze dan dalam kalimat Laney uncles crazy, ain't he?. Dalam klausa 'Cause you're scared, I ain't there? terdapat kata cause yang biasanya ditemukan dalam bentuk tuturan. Dalam klausa ini, maksud penggunaan cause ini adalah because yang dalam bahasa Indonesia berarti "karena". Dalam lirik lagu atau bahkan percakapan sehari-hari, hal seperti ini sangat sering dijumpai. Maksud seseorang menggunakan kata cause padahal dia bermaksud mengucapkan because adalah untuk penghematan atau penyingkatan (shortening). Dua kata ini memiliki arti yang sangat berbeda dan juga digunakan dalam konteks yang berbeda pula. Maksud penutur kata tersebut adalah mengucapkan konjungsi because yang berarti "karena", namun sering disingkat pengucapannya menjadi cause yang merupakan verb atau noun. Fenomena seperti ini sangat sering dijumpai dalam lagu yang dinyanyikan dan juga dalam percakapan sehari-hari. Dua kata ini memiliki arti yang sangat berbeda dan juga digunakan dalam konteks yang berbeda pula. Dalam SE, because digunakan sebagai konjungsi atau penghubung elemen atau kata dalam sebuah kalimat. Sementara itu, cause digunakan sebagai verb atau noun dalam sebuah kalimat tergantung konteksnya.

Penggunaan BE juga terdapat klausa 'Cause you're scared, I ain't there?, Lookin' puzzled, in a daze dan dalam kalimat Laney uncles crazy, ain't he?. Penggunaan BE dalam klausa 'Cause you're scared, I ain't there? dan kalimat Laney uncles crazy, ain't he? , yaitu ain't yang dalam SE adalah am not. Ain't umum digunakan oleh banyak pembicara situasi percakapan lisan informal, terutama di daerah dengan dialek tertentu. Penggunaannya seringkali sangat stigmatisasi, dan pengguna kata ini sering ditandai dengan status ekonomi dan tingkat pendidikan yang rendah. Eminem tinggal didaerah Detroit yang mayoritas penduduknya orang kulit hitam. Cara berbicara dan mengekspresikan dirinya sangat dipengaruhi lingkungannya tinggal dahulu. Hal inilah yang sangat mempengaruhinya dalam memilih kata-kata dalam lirik lagunya. Penggunaan BEV juga terdapat pada klausa Lookin' puzzled, in a daze, yaitu pada kata lookin. Perubahan fonetik ng /y/ di akhir leksikal looking, pada morfem -ing, yang merupakan fonetik velar nasal, menjadi fonetik alveolar nasal /n/. Morfemnya pun juga berubah menjadi -in, dan kata looking diucapkan menjadi lookin. Peristiwa penyederhanaan collocation ini merupakan ciri dari penggunaan Bahasa Inggris dalam kerangka BEV.

Dalam bait kedua ini menunjukkan bahwa sebagai seorang ayah Eminem ingin memberikan kehidupan yang lebih baik kepada putrinya. Kehidupan yang tidak pernah ia dapatkan ketika kecil dulu. Sebagai seorang rapper terkenal Eminem tidak ingin putrinya melihat berbagai hal buruk dalam perjalanan kariernya maupun kehidupan pribadinya. Karena itu ia berusaha keras menjauhkan kehidupan kedua putrinya dari cahaya gemerlap kehidupan selebriti agar mereka memiliki hidup normal seperti anak-anak lainnya.

\section{Bait ketiga merupakan chorus}

(1) Now hush little baby, don't you cry

(2) Everything's gonna be alright

(3) Stiffen that upper lip up little lady, I told ya

(4) Daddy's here to hold ya through the night

(5) I know mommy's not here right now and we don't know why 
(6) We fear how we feel inside

(7) It may seem a little crazy, pretty baby

(8) But I promise momma's gonna be alright

Penggunaan BEV juga terdapat dalam bait ketiga, yaitu. Kata gonna ini merupakan penyederhanaan kata going to. Klausa Everything's gonna be alright ini menyingkat kolokasi (collocation) going to menjadi gonna. Peristiwa penyederhanaan collocation ini merupakan ciri dari penggunaan Bahasa Inggris dalam kerangka BEV. Penggunaan American slang juga terdapat dalam klausa But I promise momma's gonna be alright, yaitu penggunaan kata momma. Momma merupakan bahasa slang America untuk menyebut ibu, kata ini biasanya digunakan dalam keluarga kulit hitam. Walaupun Eminem adalah rapper kulit putih tetapi ia tumbuh dan besar di lingkungan komunitas kulit hitam. Sehingga bahasa yang digunakan komunitas kulit hitam terbiasa ia dengar dan pada akhirnya mempengaruhi pemilihan kata dalam setiap lirik lagunya. Pada bait ini Eminem juga menggunakan kata slang lainnya yaitu ya dalam klausa Stiffen that upper lip up little lady, I told ya dan kalimat Daddy's here to hold ya through the night. Kata ya merupakan slang yang bermakna you. Penggunaan BEV dan slang dalam lagu hiphop adalah hal yang lumrah kerna penggunaan kata ini lebih nyaman didengar dibanding menggunakan kata dalam bahasa Inggris formal.

Bait ketiga ini menunjukkan ketegaran seorang ayah yang ingin memastikan bahwa kedua putrinya terlindungi, Eminem pasti akan melindungi kedua putrinya walaupun ibu mereka pergi entah kemana. Bagi Eminem, ia tidak ingin kedua putrinya hidup seperti dirinya yang kurang mendapatkan kasih sayang dari orang tuanya. Walaupun tanpa kehadiran seorang ibu, Eminem tetap memberikan kasih sayang yang patut didapatkan kedua putrinya.

\section{Bait keempat}

(1) It's funny

(2) I remember back one year when daddy had no money

(3) Mommy wrapped the christmas presents up

(4) And stuck'em under the tree and said some of 'em were from me

(5) 'Cause daddy couldn't buy 'em

(6) I'll never forget that christmas I sat up the whole night crying

(7) 'Cause daddy felt like a bum, see daddy had a job

(8) But his job was to keep the food on the table for you and mom

(9) And at the time every house that we lived in

(10) Either kept getting broke into and robbed

(11) Or shot up on the block and your mom was saving money for you in a jar

(12) Tryin' to start a piggy bank for you so you could go to college

(13) Almost had a thousand dollars till someone broke in and stole it

(14) And I know it hurt so bad it broke your momma's heart

(15) And it seemed like everything was just startin' to fall apart

(16) Mom and dad was arguin' a lot so momma moved back

(17) On the chalmers in the flat one bedroom apartment

(18) And dad moved back to the other side of 8 mile on Novara

(19) And that's when daddy went to california with his CD and met Dr. Dre

(20) And flew you and momma out to see me

(21) But daddy had to work, you and momma had to leave me

(22) Then you started seeing daddy on the TV. And momma didn't like it

(23) And you and Laney were to young to understand it

(24) Papa was a rollin' stone, momma developed a habit

(25) And it all happened too fast for either one of us to grab it

(26) I'm just sorry you were there and had to witness it first hand

(27) 'Cause all I ever wanted to do was just make you proud 
Now I'm sittin' in this empty house, just reminiscing

Lookin' at your baby pictures, it just trips me out

To see how much you both have grown, it's almost like you're sisters now

Wow, guess you pretty much are and daddy's still here

Laney I'm talkin' to you too, daddy's still here

I like the sound of that, yeah

It's got a ring to it don't it?

Shh, momma's only gone for the moment

Pada bait ke empat ini, Eminem masih menggunakan bahasa BEV dalam lirik lagunya, yaitu cause, tryin', startin', rollin', sittin', dan talkin'. Dapat kita temui fenomena BEV pada kata tryin', startin', rollin', sittin', dan talkin' yang cirinya juga sama seperti beberapa kalimat sebelumnya, yaitu perubahan fonetik $n g / \mathrm{y} /$ di akhir leksikal getting berubah, sehingga morfem ing yang merupakan fonetik velar nasal berubah menjadi fonetik alveolar nasal /n/. Morfemnya pun juga berubah menjadi -in, dan kata trying, starting, rolling, sitting, dan talking diucapkan menjadi tryin', startin', rollin', sittin', dan talkin'. Maksud penggunaan cause ini adalah because yang dalam bahasa Indonesia berarti "karena". Dalam lirik lagu atau bahkan percakapan seharihari, hal seperti ini sangat sering dijumpai. Maksud seseorang menggunakan kata cause padahal dia bermaksud mengucapkan because adalah untuk penghematan atau penyingkatan (shortening). Dua kata ini memiliki arti yang sangat berbeda dan juga digunakan dalam konteks yang berbeda pula. Maksud penutur kata tersebut adalah mengucapkan konjungsi because yang berarti "karena", namun sering disingkat pengucapannya menjadi cause yang merupakan verb atau noun. Fenomena seperti ini sangat sering dijumpai dalam lagu yang dinyanyikan dan juga dalam percakapan sehari-hari.

Bait ke empat ini menunjukkan bahwa sebagai seorang ayah, Eminem merasa tidak berguna karena ia tidak memiliki pekerjaan tetap dan juga uang. Pada saat itu Eminem hanya lah seorang penyanyi rapper yang tidak terkenal dan bekerja dengan upah minimum sebagai tukang masak dan mencuci piring di restoran Lodge Gilbert di daerah Shores St Clair. Kehidupan Eminem berubah ketika ia pergi ke California dengan membawa CD demo dan bertemu Dr. Dre. Semenjak itu kehidupan Eminem berubah menjadi rapper terkenal dan kaya raya namun hal ini tidak membuat istrinya senang. Perjuangan pribadi Eminem, penyalahgunaan obat dan alkohol, perceraian dengan istrinya dan penyalahgunaan obat oleh sang istri yang mengakibatkan keluar masuk panti rehabilitasi tergambar jelas dalam setiap lirik lagunya.

\section{Bait ke lima}

(1) And if you ask me too

(2) Daddy's gonna buy you a mockingbird

(3) Ima give you the world

(4) Ima buy a diamond ring for you

(5) Ima sing for you

(6) I'll do anything for you to see you smile

(7) And if that mockingbird don't sing and that ring don't shine

(8) Ima break that birdies neck

(9) I'd go back to the jeweler who sold it to ya

(10) And make him eat every carat don't f*** with dad (ha)

Pada bait ke lima ini, Eminem menggunakan kata slang yaitu Ima. Ima merupakan bahasa slang untuk menyatakan I am going to. Dalam bait ini Eminem juga menyebutkan mockingbird. Mockingbird adalah burung yang terkenal karena menirukan nyanyian burung lain, suara serangga ataupun amfibi. Mockingbird dalam lirik lagu ini mengisahkan bagaimana kehidupan Eminam dulu dan sekarang. Ia seperti mengisahkan kembali apa yang ia rasakan ke dalam lirik lagunya. Sama seperti burung Mockingbird yang pintar menirukan suara binatang lain. 


\section{Transklulturasi dalam Lirik Lagu}

Proses transkulturasi yang terjadi pada lagu Mockingbird adalah penggunaan Black English yang aslinya hanya diguankan oleh orang kulit hitam saja, namun ia mengalami transkulturasi sehingga bisa digunakan oleh orang kulit putih seperti Eminem. Transkulturasi bisa terjadi dalam lagu ini karena adanya kontak antara Eminem yang merupakan orang kulit putih dengan orang kulit hitam di kawasan Detroit, lingkungan Eminem tinggal saat dahulu. Bentuk Black English yang digunakan Eminem dalam lagu Mockingbird di antaranya tryin', startin', rollin', sittin', dan talkin'. Selain untuk transkulturasi, Eminem menggunakan BEV juga karena ia merasa bahwa dirinya adalah bagian dari komunitas orang kulit hitam Detroit yang berkomunikasi dengan menggunakan Black English, slang Amerika, dan kata-kata kasar. Komunitas tersebut menggunakan kata-kata kasar dalam berkomunikasi karena mereka merupakan pihak yang termarjinalisasi. Jika mereka berpendidikan tinggi dan bukan kaum marginalized maka yang digunakan untuk berkomunikasi bukanlah kata-kata kasar. Tidak menutup kemungkinan juga kalau mereka menggunakan kata-kata kasar, tapi penggunaannya hanya sebatas pada ekspresi marah terhadap sesuatu yang sudah sangat keterlaluan, bukan digunakan untuk berkomunikasi.

Penggunaan bahasa Inggris informal, slang Amerika, dan juga BEV dalam lagu tersebut memiliki maksud tertentu. Pertama, penggunaan bahasa informal dan juga bahasa slang Amerika menunjukkan identitas Eminem, si penyanyi sekaligus pencipta lirik lagu tersebut, sebagai generasi muda Amerika yang suka pada kebebasan berekspresi. Kedua, penggunaan Black English atau BEV dalam lagu juga menunjukkan identitas Eminem dan ideologi dibalik ragam bahasa Inggris tersebut. Dalam hal ini, identitas Eminem adalah sebagai bagian dari komunitas kulit hitam Amerika yang menggunakan BEV sebagai pedoman percakapan sehari-hari. Eminem yang aslinya adalah orang Amerika kulit putih hidup dan besar di wilayah Detroit, Amerika, yang mayoritas penduduknya adalah orang kulit hitam. Dalam hal ini ia menunjukkan identitasnya sebagai orang kulit putih yang anti-rasis. Ideologi anti-rasis ini diusung oleh Eminem dengan cara menyanyikan lagu hiphop yang aslinya merupakan budaya orang kulit hitam Amerika.

\section{SIMPULAN}

Melalui hasil analisis lirik lagu Mockingbird milik Eminem, dapat disimpulkan bahwa kata-kata yang dipilih dalam lirik lagunya merupakan representasi dari jati dirinya sebagai seorang Eminem, yang tumbuh dan hidup di lingkungan komunitas kulit hitam Detroit, Amerika. Eminem merupakan seorang kulit putih Amerika yang menggunakan budaya hiphop Amerika, yang berasal dari budaya orang kulit hitam Amerika (African American), untuk memperkenalkan dirinya pada pasar musik Amerika. Ia sangat terpengaruh dengan budaya hiphop tersebut karena lingkungan tempat ia tinggal dahulu. Terdapat relasi yang terjadi dalam lirik lagu tersebut, yaitu antara Eminem sebagai pembuat teks dan sekaligus penyanyi lagu, serta dengan para pendengar lagunya. Maksud dan tujuan dari lagu ini dibuat adalah untuk memberikan sebuah gambaran tentang sepenggal kisah hidupnya yang seorang ayah dan juga rapper terkenal. Terakhir, terdapat proses arus trankulturasi atau arus lintas budaya dalam lirik lagu tersebut. Dalam lagu Eminem, yang merupakan orang kulit putih, terdapat bentuk budaya hiphop yang bergerak, berubah, dan digunakan kembali untuk membentuk sebuah identitas yang baru. Dalam hal ini, budaya hiphop yang aslinya milik orang kulit hitam Amerika mengalami transkulturasi dengan membentuk sebuah identitas baru, identitas Eminem sebagai penyanyi hiphop kulit putih asal Amerika. 


\section{DAFTAR PUSTAKA}

Diilard, J.L. 1972. Black English: It's History and Usage in the United States. New York: Random House.

Fairclough, Norman. 1995. Critical Discourse Analysis: The Critical Study of Language. London: Longman.

Hornby, A.S. 2000. Oxford Advanced Learner's Dictionary 6th edition. Oxford: Oxford University Press.

Labov, William. 1972. Language in the Inner city: studies in the Black English Vernacular. Pennsylvania: University of Pennsylvania Press.

Moleong, Lexy J. 2001. Metodologi Penelitian Kualitatif. Bandung: Remaja. Rosdakarya.

Pennycook, Alastair. 2007. Global englishes and transcultural flows. New York: Routlegde.

Philips, L. \& M. W. Jorgensen. 2002. Discouse Analysis as Theory and Method (1st Edition). London: Sage Publication Ltd.

Yuwono, U. 2005. Pesona Bahasa: Langkah Awal Memahami Linguistik. Jakarta: Gramedia Pustaka Utama. 